\title{
La protección al Derecho de Autor en el Perú
}

\author{
Rosalía Quiroz de García \\ Departamento Académico de Bibliotecología \\ y Ciencias de la Información
}

\section{LA PROPIEDAD INTELECTUAL}

Antecedentes.

ar. 1 perfeccionar Juan Gutenberg (1440) la prensa, y con él sistema de 14 impresión, permitió la reproducción de libros a gran escala y el auge de la industria editorial y del libro, que en el curso de la historia se convirtió en uno de los vehículos más importantes en la difusión de las ideas del hombre y de la cultura en general. Durante la época delfeudalismo se restringió y censuró la libre circulación de las ideas, consecuentemente del libro, sin embargo, con el tiempo, afirma de León Penagos (1993): "El libro difundió las ideas del enciclopedismo francés y creó la conciencia liberal; asimismo, sirvió para subyugar y generar el servilismo de los indios americanos, pero también para liberar al Nuevo Mundo del dominio europeo".'1

Durante la RevoluciớnFrancesa por Leydequeonvención, se proclamó la propiedad privada e individual como garantía del ciudadano francés, acontecimiento que permitió se dieran los primeros pasos para el reconocimiento del "Derecho de propiedad del autor" como facultad exclusiva para él, sus herederos y cesionarios. Rubén Ugarteche afirma que Le Chapellier pronunció la inmortal frase: "la más sagrada, la más legítima, la más personal de todas las propiedades es la obra fruto del pensamiento de un autor". ${ }^{2}$ Posteriormente en 1948, la ONU aprueba la Declaración Universal de los Derechos Humanos, que señala en su el Art. 27, inc. 2. "Toda persona tiene derecho a la protección de los intereses morales y materiales que le correspondan por razón de las producciones científicas, literarias o artísticas que sean autores". En el Perú se promulgaron importantes normas respecto a la protección de la propiedad

' De León Penagos, Jorge (1993). El libro. México. Editorial Trillas, p. 19.

${ }^{2}$ Ugarteche Villacorta, Rubén. Presentación. En: Busta Grande, Fernando (1997). El Derecho de Autor en el Peri. Lima, Grijley, p. 7. 
intelectual que datan desde el año 1849 , como un valioso antecedente en la evolución del Derecho de Autor en nuestro país.

\section{ELDERECHO DEAUTOR}

"Derecho de Autor, el que tiene toda persona sobre la obra que produce: y especialmente, el que corresponde por razón de las obras literarias, artísticas, científicas, técnicas, para disponer de ellas por todos los medios que las leyes autorizan". ${ }^{3}$ Conjunto de normas que regulan y protegen los derechos morales y patrimoniales que corresponden a la persona natural o jurídica. El Estado protege tales derechos que abarca toda la obra producida por el ingenio humano, sean de carácter literaria, artística, científica e industrial, en suma toda la producción de la mente en sus diversas manifestaciones.

Este conjunto de derechos que la ley reconoce al autor de una obra, le permite divulgarla, reproducirla o transmitirla (distribuirla) al público, bajo algún tipo de soporte físico, pudiendo ser a través del papel impreso, la grabación sonora, la cinta audiovisual, el diskette, etc.

Marco jurídico del Derecho de Autor en el Perú Y el mundo

\section{Biblioteca de Ietras}

Desde la independencia del Perú se han promulgado diferentes normas legales destinadas a la protección de los derechos de autor, a manera de recopilación muy genérica mencionaremos cronológicamente las más importantes:

1823. La primera Constitución del Perú, reconoció y declaró la inviolabilidad de la Propiedad Intelectual.

1849. Primera Ley de propiedad intelectual, dada en el Gobierno de Castilla -9 artículos- los que en términos muy genéricos señalaban los alcances de este derecho, a quiénes y al tipo de producción afectaba, el tiempo que duraba la protección (30 años), el procedimiento para la inscripción; y, las sanciones para casos de infracción. Disponía, además, depositar en las Bibliotecas Públicas las ediciones de las obras que se publicaban en su localidad, ley que mantuvo su vigencia hasta 1961 .

${ }^{3}$ Cabanillas, Guillermo (1976). Diccionario de Derecho Usual. Buenos Aires: Ed., Eliasta, p.641. 
1915. Por Resolución Suprema, el Ministerio de Instrucción de entonces, dispone que la Biblioteca Nacional abra un libro especial de Registro Cronológico de Autores.

1961. Ley $\mathrm{N}^{\circ} 13714$ de Derecho de Autor, promulgada durante el Gobierno de Manuel Prado, con características más amplias que la anterior, 159 artículos referidos al tipo de producción intelectual que protege, los titulares del derecho de autor, la duración y los atributos, limitación, el registro, la trasmisión de los derechos, las infracciones y las medidas preventivas. Creaba además en la Biblioteca Nacional del Perú, el Registro Nacional de Derecho de Autor, cuyo funcionamiento fue reglamentado el siguiente año bajo la denominación de Oficina de Bibliografía y Registro Nacional de Derecho de Autor.

1982. Ley 23506 de Hábeas Corpus y Acción de Amparo, Garantías Constitucionales que alcanzan a proteger los derechos de creación artística, intelectual y científica.

1983. Ley 23535 sanciona los actos de piratería en el país.

1984. El nuevo Código Civil, establece la protección jurídica de los derechos de autor y del inventor. Título II. Derechos de la Persona, Art. 18.Derechos de Autor y del Inventor-Art. 886, inc. 5. Son bienes muebles: los derechos patrimoniales de autor, de inventor, de patente, nombres, marcas, etc. Dentro de la Sociedad de Gananciales, cada uno es dueño del producto de su creación.

1985. Ley de Depósito Legal $\mathrm{N}^{\circ} 24182$, establece que los autores e impresores con tiraje mayor a los 1000 ejemplares, remitirán a la Biblioteca Nacional seis ejemplares de cada edición.

1988. El Perú integra la Convención de Berna, Convenio Internacional para la protección de las obras literarias y artísticas, el mismo que entró en vigencia a partir de 1989.

1992. Decreto Ley 25688 crea el Instituto de Defensa de la Competencia y la Propiedad Intelectual (INDECOPI) y el Tribunal de Defensa de la Competencia, en cuya estructura orgánica y funcional la integra la Oficina de Derecho de Autor. 
1993. La Constitución Peruana, art. 2, inc. 8.- Reconoce la libertad de creación intelectual, artística, técnica y científica, así como a la propiedad sobre dichas creaciones y a su producto.

1994. Código Penal. Libro II, Título VII, Capítulo I, artículos 216 al 221, sanciona los delitos contra los derechos intelectuales, que luego han sido modificados en 1996 con penas más severas que van hasta los ocho años de cárcel.

1996. Decreto Legislativo 822 Ley de Derecho de Autor (220 artículos), el mismo que modifica el contenido de la ley 13714 , luego de 35 años de vigencia.

1997. Ley de Depósito Legal № 26905 en la Biblioteca Nacional del Perú, están obligados a cumplir con esta ley, los editores, impresores, productores o fabricantes de toda obra impresa, grabación fónica, programa de computadora, videocinta y cualquier otro soporte que registre información, que se edite o grabe, bajo cualquier sistema o modalidad, en el territorio nacional, así como a los extranjeros que distribuyan en el territorio nacional. Se entregará tres ejemplares de cada libro, folleto o documento con más de 1000 ejemplares; dos ejemplares de publicaciones periódicas, un ejemplar de otros materiales especiales: discos compactos, películas, etc.

1998. Decreto Supremo N 017-98-ED. Reglamento de la Ley de Depósito Legal en la Biblioteca Nåcjonalderferú.e. Letras

\section{"Jorge Puccinelli Converso "}

En la vigésimo octava reunión anual de la UNESCO; realizada en París en 1995, mediante Resolución N 318 se instauró el 23 de abril como "Día Mundial del Libro y del Derecho de Autor".

\section{CONVENIOS INTERNACIONALES SOBRE LA PROPIEDAD INTELECTUAL}

A. Convenio de Berna para la protección de las obras literarias y artísticas

Sistema Internacional de Derecho de Autor (9 de setiembre de 1886), completado en París (1896), revisado en Berlín (1908) y completado en Berna (1914), Roma (1928), Bruselas (1948), Estocolmo (1967) y París (1979). Con-venio suscrito por más de 128 países, con la finalidad de proteger del modo más eficaz y uniforme los derechos de los autores sobre sus obras literarias y artísticas. El Perú suscribió este Convenio en 1988 encontrándose vigente desde 1989, época 
en la que además se integraron los países de México y Argentina; este Convenio se sustenta en los siguientes principios:

a) Trato Nacional para los autores, quienes tienen protección en todos los Estados de la Unión.

b) La protección es automática sin necesidad de cumplir formalidades, basta con ser parte del Estado que integra la Convención.

c) $\mathrm{Al}$ ser la protección automática, no se tiene que probar que la ley lo defiende y ampara, basta que ella exista.

d) La protección mínima, reconoce derechos mínimos los derechos económicos y morales, protección que permite obtener medidas cautelares en caso de su infracción.

\section{B. Convención de Roma}

Denominada también Conyención Internacional sobre la Protección de los Artistas Intérpretes o Ejecutantes, los Productores de Fonogramas y los Organismos de Radiodifusion (1961). Su finalidad es la protección de tres tipos de autores, los artistas, intérpretes o ejecutantes, sobre sus interpretaciones, representaciones a ejecuciones; el derecho de los productores de fonogramas; el derecho de los organismos de radiodifusión, sobre difusión y transmisiones radiodifundildảso EstazConvención es administrada por la Organización Mundial de ja Propiedadintelectual (QMPI) con la participación de la UNESCO y la OIT, actualmente tiene cerca de medio centenar de países miembros. Al igual que la Convención de Berna, también protege los derechos patrimoniales (explotación económica de la obra) y los derechos morales (derecho al nombre del artista).

\section{Acuerdo General de Tarifas y Aranceles (GATT)}

La Ronda de Negociaciones de Uruguay que se inició en 1987 y concluyó en 1993, incluyó en uno de sus acuerdos el tema de los derechos intelectuales referidos al comercio. Este acuerdo tuvo por finalidad uniformar los sistemas arancelarios y tarifarios de los países miembros, dentro del aspecto netamente comercial sobre los derechos intelectuales; es decir, de aquella parte que puede ser objeto de transacción económica, mencionándose al software, las bases de datos y las obras cinematográficas. 


\section{Régimen común sobre Derecho de Autor y derechos conexos}

Decisión $N^{\circ} 351$ de la Comisión del Acuerdo de Cartagena, tratado de carácter regional, aprobado en Lima, diciembre de 1993; cuya finalidad fue uniformar las normas que protegen los derechos intelectuales en los distintos países de la región, prueba de ello es que el contenido de la Ley de Derecho de Autor aprobado por el Perú en 1996, tiene aspectos similares al aprobado en la Decisión $\mathrm{N}^{\circ} 351$, por lo que es considerado el antecedente inmediato para la aprobación del Decreto Legislativo $N^{\circ} 822$. Esta Decisión señala en sus dos primeros artículos:

Artículo 1. Las disposiciones de la presente Decisión tiene por finalidad reconocer una adecuada y efectiva protección a los autores y demás titulares de derechos, sobre las obras del ingenio, en el campo literario, artístico o científico, cualquiera que sea el género o forma de expresión y sin importar el mérito literario o artístico ni su destino. Asimismo, se protegen los Derechos Conexos a que se hace referencia en el Capítulo $\mathrm{X}$ de la presente Decisión.

Artículo 2. Cada país Miembro concederáa los nacionales de otro país, una protección no menos favorables que la reconocida a sus propios nacionales en materia de Derecho de Autor y Derechos Conexos.

\section{LEY SOBRE EL DERECHO゚DEALTOR (DECREFO LEGISLATIVO N822) "Jorge Puccinelli Converso»}

Luego de aprobada la Decisión 351 de la Comisión del Acuerdo de Cartagena, el Gobierno Peruano que ya había adoptado el Convenio de Berna y, con la finalidad de asegurar a los autores y demás titulares una efectiva protección, promulgó este Decreto, cuyos aspectos más importantes son tratados a continuación.

\section{Obras protegidas por El Derecho de Autor.}

El derecho de autor se origina al momento mismo de la creación de una obra, la que a su vez puede ser una obra literaria, artística o científica, constituyéndose así en el objeto de protección de la ley. El Dec. Leg. $N^{\circ} 822$, señala en su Artículo $5^{\circ}$.- Están comprendidas entre las obras protegidas las siguientes:

a) Las obras literarias expresadas en forma escrita, a través de libros, revistas, folletos u otros escritos.

b) Las obras literarias expresadas en forma oral, tales como las conferencias, 
alocuciones y sermones o las explicaciones didácticas.

c) Las composiciones musicales con letra o sin ella.

d) Las obras dramáticas, dramático-musicales, coreográficas, pantomímicas y escénicas en general.

e) Las obras audiovisuales.

f) Las obras de artes plásticas, sean o no aplicadas, incluidos los bocetos, dibujos, pinturas, esculturas, grabados y litografías.

g) Las obras de arquitectura.

h) Las obras fotográficas y las expresadas por un procedimiento análogo a la fotografía.

i) Las ilustraciones, mapas, croquis, planos, bosquejos y obras plásticas relativas a la geografía, la topografía, la arquitectura o las ciencias.

j) Los lemas y frases en la medida que tengan una forma de expresión literaria o artística, con características de originalidad.

k) Los programas de ordenador.

l) Las antologías o compilaciones de obras diversas o de expresiones del folklore, y las bases de datos, siempre que dichas colecciones sean originales en razón de la selección, coordinación o disposición de su contenido.

m) Los artículos periodísticos, sean o no sobre sucesos de actualidad, los reportajes, editoriales y comentarios.

n) En general, toda otra producción del intelecto en el dominio literario o artístico, que tenga características de originalidad y sea susceptible de ser divulgada o reprodycida por cualquier medio o procedimiento, conocido o por conocerse.

\section{«Jorge Puccinelli Converso»}

\section{OBRAS DERIVADAS.}

De acuerdo a su denominación todas aquellas obras secundarias producidas en base a las obras primarias, y que revistan características de originales, entre ellas tenemos:

a. Las traducciones, adaptaciones.

b. Las revisiones, actualizaciones y anotaciones.

c. Los resúmenes y extractos.

d. Los arreglos musicales.

e. Las demás transformaciones de una obra literaria o artística o de expresiones del folklore. 
OBRAS NO PROTEGIDAS.

La ley establece cuáles son aquellas obras que caen en el dominio público o científico, y por tanto no son objeto de protección, así tenemos:

a. Las ideas contenidas en las obras literarias o artísticas, los procedimientos, métodos de operación o conceptos matemáticos en sí, los sistemas o el contenido ideológico o técnico de las obras científicas, ni su aprovechamiento industrial o comercial.

b. Los textos oficiales de carácter legislativo, administrativo o judicial, ni las traducciones oficiales de los mismos, sin perjuicio de la obligación de respetar los textos y citar la fuente.

c. Las noticias del día, pero, en caso de reproducción textual, deberá citarse la fuente de donde han sido tomadas.

d. Los simples hechos o datos.

Derechos Que protege la Ley de Derecho de Autor

Esta norma protege básicamente dos tipos de derechos, los derechos morales y los derechos patrimoniales.

\section{A. Derechos morales}

Aquellos derechos inherentes al autor de una obra, y que nadie puede hacer uso de ellos, salvo con la autorizacion expresa del titular. Estos derechos se caracterizan por ser perpetuos (duran toda la vida del autor), inalienables (sólo corresponden al autor), inembargables, irrenunciables e imprescriptibles (no deja de tener vigencia con el paso del tiempo), estos derechos pueden ser transmitidos a sus herederos o causahabientes, están constituidos por:

a) El Derecho de divulgación, la facultad del autor de decidir si su obra se mantiene inédita o ha se ser divulgada bajo la forma que mejor le convenga.

b) El Derecho de paternidad (derecho al nombre), exigir que se le reconozca como autor de una obra, y que éste lleve su nombre o seudónimo o se mantenga anónima.

c) El Derecho de integridad, facultad de oponerse a toda deformación, modificación, mutilación o alteración.

d) El Derecho de modificación o variación, el autor puede modificar su obra 
respetando los derechos adquiridos por terceros.

e) El derecho de retiro de la obra del comercio, suspender cualquier forma de utilización de la obra,

f) El derecho de acceso, acceder al ejemplar único o raro cuando se halle en poder de terceros.

\section{B. Derechos patrimoniales}

Es el derecho que tiene el autor, de explotar su obra y beneficiarse económicamente de ella bajo cualquier forma o procedimiento, durante toda su vida y 70 años después de muerto (cuando se trate de sus herederos). En las obras de colaboración cuenta la protección desde la muerte del último coautor. Transcurrido este tiempo, se extingue el derecho patrimonial y la obra pasa al dominio público como patrimonio cultural de la nación. Este derecho permite realizar, autorizar o prohibir las siguiente acciones:
a. La reproducción de la obra por cuaqquier forma o procedimiento.
b. La comunicación al público de la obra por cualquier medio.
c. La distribución al público de la obra.
d. La traducción, adaptación, arreglo u otra transformación de la obra.
e. La importación al Perritorionacionalde copias de fa obra hechas sin autorización del titulardel derechoppor cualquiez medio incluyendo mediante transmisión.

Sujetos del Derecho de Autor

La ley distingue entre el sujeto en calidad de titular originario y titular derivado.

\section{A. Titular originario}

Toda persona natural o jurídica que haya creado la obra; si ésta fuera una obra anónima o por seudónimo, el ejercicio de los derechos en calidad de titular originario, le corresponde a la persona natural o jurídica que la divulgue con el consentimiento del autor o los coautores de común acuerdo. 


\section{B. Titular derivado}

Son aquellas personas naturales o jurídicas, a quienes se les ha trasmitido el derecho sobre las obras, por cesión mediante acto entre vivos o transmisión mortis causa, con la finalidad de usufructuar legalmente el producto intelectual del autor.

\section{ELAMPARO DEL ESTADO A LOS DERECHOS DELAUTOR}

Antes del funcionamiento de INDECOPI, la entidad encargada por ley para efectos de los Registros de Derechos de Autor era el Registro Nacional de Derechos de Autor en la Biblioteca Nacional que funcionó hasta abril de 1996, fecha en que sus funciones fueron transferidos a la Oficina de Derecho de Autor en INDECOPI.

\section{EL REGISTRO}

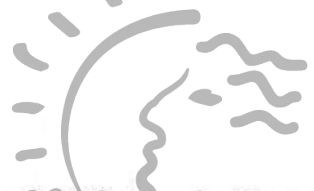

La norma señala, que la Oficina de Derechos de Autor, llevará el Registro Nacional del Derecho de Autor y Derechos Conexos, donde podrán inscribirse las obras del ingenig y los demás bienes intelectuales protegidos por esta ley, así como los convenios o contratos que en cualquier forma confieran, modifiquen, transmitan, "graven o extingan derechos" patrimoniales, o por los que se autoricen modificaciones a la obra. El registro es meramente facultativo para los autores y sus causahabientes y no constitutivo, de manera que su omisión no perjudica el goce ni el ejercicio pleno de los derechos reconocidos y garantizados por la presente ley.

Este acto de anotar, inscribir, transcribir en el Registro del Derecho de Autor y Derechos Conexos (interpretaciones, ejecuciones de los artistas, intérpretes o ejecutantes, fijaciones fonográficas) la titularidad de una obra, no es constitutivo de derecho, lo que significa que el derecho del autor no nace a partir de su registro, sino desde el momento que el autor crea la obra, como una facultad inherente sólo a la persona humana.

El INDECOPI, a través de sus oficinas a nivel nacional permite la inscripción de las obras protegidas por la Ley de Derechos de Autor, sin embargo, la omisión de este acto no impide el ejercicio de los derechos a los titulares. Por otro lado, se 
presume que toda persona tiene conocimiento del contenido de las inscripciones, por ello se denomina Registro en condición de Público, y se presume la buena de quienes contratan en base a la inscripción en el Registro. Registrar una obra con anterioridad a otro, determina la preferencia de los derechos ya que sus efectos están en relación directa a la fecha y hora de la presentación en el Registro, la misma que permite demostrar más adelante que los derechos que se declaran, son ciertos en tanto no se pruebe lo contrario. Acción que puede ser contradicha en la vía judicial cuyo fallo adquiere la condición de cosa juzgada.

\section{Características del Registro de DeRECHO de Autor}

a) Es facultativa. Registrar una obra no tiene carácter obligatorio, el titular del derecho es quien voluntariamente decide si registra o no su creación, y de hacerlo éste tiene un valor sólo declarativo para los autores y sus causahabientes; el hecho de no registrar una obra-reiteramos-no impide gozar y ejercitar los derechos reconocidos y garantizados por la ley.

b) Es declarativa. Los actos inscritos en el Registro (aquello que declara el autor) se presumen ciertos en tanto no se pruebe lo contrario.

c) Es constitutivo de derechos. Si bien es cierto que la inscripción de una obra no es obligatoria, sin embargo, este acto es un medio de publicidad y una prueba de anterioridad para demestrar la titularidad del derecho, pero que puede admitir prueba en contrario. ElRegistro es la condición esencial para que el Estado le otorgue protección al autor en caso que sus derechos sea vulnerados.

d) Es exclusiva. El titular de este derecho puede excluir a cualquier otro de su explotación económica.

e) Es temporal. Los derechos del titular de una obra duran toda la vida del autor, y se extiende a sus herederos por espacio de 70 años luego de muerto el titular.

\section{INFRACCIÓN A LOS DERECHOS DE AUTOR}

El Estado ha previsto y pone en marcha diferentes procedimientos cuando se infringe los derechos morales y patrimoniales que corresponden a las personas naturales o jurídicas, tipificándolas como delitos o faltas, pasibles de ser sancionadas tanto en la vía administrativa, civil o penal . 


\section{A. Acción administrativa}

A través del procedimiento administrativo, los titulares de los derechos de autor podrán denunciar la infracción de sus derechos ante la Oficina de Derecho de Autor del Indecopi, en su condición de Autoridad administrativa competente; para lo cual el titular del derecho está obligado a ofrecer las pruebas necesarias para probar su denuncia, de ser así, la autoridad está facultada para ordenar las siguientes medidas preventivas o cautelares:

a. La suspensión o cese inmediato de la actividad ilícita.

b. La incautación o comiso y retiro de los canales comerciales de los ejemplares producidos o utilizados y del material o equipos empleados para la actividad infractora.

c. La realización de inspección, incautación o comiso sin aviso previo.

Además de estas medidas, la Oficina de Derecho de Autor, también está facultada para imponer sanciones, que van desde la:

a. Amonestación

b. Multa de hasta 150 Unidades Impositivas Tributarias

c. Reparación de las omisiones

d. Cierre temporal hasta por treinta días del establecimiento

e. Cierre definitivodel establecimiento

f. Incautación o comiso definitivo

g. Publicación de la resolucion a costa del infractor

Si se considera la existencia de un presunto delito, esta Oficina podrá interponer denuncia penal ante el Ministerio Público.

\section{B. Acción civil}

Se tramita ante el Poder Judicial, de acuerdo al Código Procesal Civil. La ley establece que los titulares de los derechos de autor, sus representantes o las sociedades de gestión colectiva, podrán pedir la indemnización de los daños materiales y morales causados por la violación a sus derechos. Cuando de por medio existe una relación contractual que crea obligaciones y su incumplimiento da lugar a una acción civil; el cese de la actividad ilícita podrá comprender la suspensión inmediata de la actividad infractora o la prohibición al infractor de 
reanudarla o el retiro del comercio de los ejemplares ilícitos y su entrega al titular de los derechos vulnerados, en su caso, o su destrucción, o también la inutilización de los moldes, planchas, matrices, negativos y demás elementos destinados a la reproducción de ejemplares ilícitos y de ser necesario la destrucción de tales instrumentos, así como la incautación de los aparatos utilizados en la comunicación pública no autorizada.

El Decreto Legislativo $N^{\circ} 822$ señala en su Artículo 198.- El Juez a instancia del titular del respectivo derecho, de su representante o de la sociedad de gestión correspondiente, ordenará la práctica inmediata de las medidas cautelares necesarias para evitar que se cometa la infracción o que se continúe o repita una violación ya realizada, en particular las siguientes:

a. El embargo de los ingresos obtenidos por la actividad ilícita, o, en su caso, de las entidades por concepto de remuneración.

b. La suspensión inmediata de la actividad de fabricación, reproducción, distribución, comunicación o importación ilícita, según proceda.

c. El secuestro de los ejemplares prodúcidos o utilizados y el del material o equipos empleados para la actividad infractora.

\section{Acción penal}

Procedimiento que ses tramita ante elePoder Jualicial, cuando se cometen faltas o delitos en contrajder los derechos intelectuales.)Amparados en el Título VII del Código Penal, Delitos contra los Derechos Intelectuales las mismas que fueron modificados en 1996: Artículos 216 al 221, penas que van de los dos a los ocho años de prisión efectiva.

Los agraviados pueden ejercer acción penal entre otros por los siguientes delitos contemplados en el Código Penal:

\section{REPRODUCCIÓN ILICITA}

Aquel que modifique, reproduzca, distribuya o comunique una obra, sin autorización previa y escrita del autor o titular de los derechos, será reprimido con pena privativa de libertad no menor de dos ni mayor de seis años y con treinta a noventa días-multa. (Artículo 217 Código Penal).

La Ley de Derecho de Autor establece algunas excepciones: 
Artículo $43^{\circ}$.- Respecto de las obras ya divulgadas lícitamente, es permitida sin autorización del autor.

a. La reproducción por medios reprográficos, para la enseñanza o la realización de exámenes en instituciones educativas, siempre que no haya fines de lucro y en la medida justificada por el objetivo perseguido, de artículos o de breves extractos de obras lícitamente publicadas, a condición de que tal utilización se haga conforme a los usos honrados y que la misma no sea objeto de venta u otra transacción a título oneroso, ni tenga directa o indirectamente fines de lucro.

b. La reproducción por reprografía de breves fragmentos o de obras agotadas, publicadas en forma gráfica, para uso exclusivamente personal.

c. La reproducción individual de una obra por bibliotecas o archivos públicos que no tengan directa o indirectamente fines de lucro, cuando el ejemplar se encuentre en so colección permanente, para preservar dicho ejemplar y sustituirlo en caso de extravío, destrucción o inutilización; o para sustituir en la colección permanente de otra biblioteca o archivo, un ejemplar que se haya extraviado, destruidd o inutilizado, siempre que no resulte posible adquirir tal ejemplar en plazo y condiciones razonables.

\section{PLAGIO}

\section{Biblioteca de Letras}

Quien difunda como propia, en todo o en parte, copiándola o reproduciéndola textualmente, o tratando de disimular la copia mediante ciertas alteraciones, a lo que se denomina plagio burdo o plagio inteligente. En caso de obras científicas, que sirven de sustento teórico a los trabajos de investigación, no se consi-dera plagio la reproducción literal, bajo la condición que éstas sean debidamente citadas. Esta competencia desleal, afecta el derecho moral, al copiar ilícitamente la producción intelectual ajena, y al derecho patrimonial, porque afecta económi-camente a quien está facultado por ley a su explotación o goce de las utilidades. Será reprimido con pena privativa de libertad no menor de dos ni mayor de o-cho años y sesenta a ciento ochenta días-multa. (Artículo 219 del Código Penal).

\section{USURPACIÓN DE PATERNIDAD}

Quien se atribuya falsamente la calidad de titular, originario o derivado, de 
cualquiera de los derechos protegidos en la legislación. Este delito afecta el derecho moral, aprovechamiento de la obra ajena, fingiendo ser el autor o disfrutando derechos ajenos, con la usurpación se ejercen los derechos pertenecientes a terceros, con la clara intención de sustituir al autor o aparecer como tal. Será reprimido con pena privativa de libertad no menor de cuatro ni mayor de ocho años y noventa a trescientos sesenticinco días-multa. (Artículo 20 del Código Penal).

La usurpación del nombre, seudónimo, nombre de arte o sigla de un autor, también es sancionado de acuerdo al art. 14 del Código Civil, el cual prescribe que la usurpación del nombre da lugar a la acción para hacerla cesar y para indemnizar daños y perjuicios a través del procedimiento civil.

\section{PIRATERla}

Constituye una de las acciones ilegales que con mayor incidencia se viene cometiendo en nuestro medio, es la impresión o reproducción ilegal, copiando otra obra que tiene éxito y que se expende públicamente sin ningún control, eva-diendo impuestos, y a menor precio que el original, grave problema que hasta la fecha no ha podido sep frenado por la entidades encargadas de sancionar este tipo de delitos, no obstante la existencia de normas severas que la sancionan, en la realidad es poco lo que se viene haciendo al respecto y lo que es peor la población tiene una percepción generalizada que existe algún nivel de compli-cidad èntré todos los acterês dé estagilegal actividad.

\section{"Jorge Puccinelli Converso»}

Hace poco Miguel A. Cárdenas en un artículo publicado en el suplemento Domingo de La República (Lima, 14 de enero de 2001), señalaba que han surgido nuevos métodos en el accionar de los piratas "traerlos directamente del extranjero y venderlos mucho antes de que lleguen a las editoriales nacionales, ganándoles a éstas el mercado y, de paso, la moral". Con lo cual se viene generando pérdidas millonarias (20 millones de dólares al año) a la industria editorial legalmente constituida, quienes por ley pagan todos sus impuestos, a diferencia del pirata que evade estos pagos, siendo sus ganancias líquidas. Por otro lado agrega: no existe un solo preso por ser pirata, esto, debido a la ineficaz labor del INDECOPI, que no obstante conocer que en el país existen no más de 12 máquinas capaces de reproducir carátulas de buena calidad, sin embargo, la inacción del Estado ha sido muy sospechosa.

Como podemos observar los derechos de autor se encuentran protegidos por el Estado, y por Convenios Internacionales de los que el Perú es signatario, 
sin embargo, poco es lo que se ha avanzado en la sanción real a los infractores, por lo que se debe incidir que, además de la difusión y concientización en la población respecto a las normas que protegen los derechos de autor y la importancia que estas tienen, es el Estado a través de sus instituciones competentes el encargado de evaluar los niveles de carga impositiva con que se grava esta actividad, así como investigar y sancionar estos delitos; de no ser así seguiremos atentando contra el progreso de la sociedad, que se sustenta en la creación literaria, artística, y científica. Tomemos el ejemplo de México, ante la intención del Gobierno del Presidente Fox (marzo 2001) de gravar con un impuesto al libro, todos los sectores de la población desde intelectuales, estudiantes, profesionales, etc. vienen realizando una verdadera cruzada por los diferentes medios al que tienen acceso, que impida esta decisión.

\section{BIBLIOGRAFIA}

BRACAMONTE ORTIZ, Guillermo

1994 Derecho de autor y derechos conexos en los paises del Acuerdo de Cartagena: Decisión 351. Lima: Fejovichs.

BUSTA GRANDE, Fernando

1997 El Derecho de Autor en el Perú. Editora Grijley. Lima.

CABANELLAS, Guillermorge Puccinelli Converso »

\section{Biblioteca de Letras}

1986

Diccionario de Derecho Usual. Editorial Heliasta, Buenos Aires, 1986.

CÓDIGO CIVIL

1995

Lima.

CÓDIGO PENAL

1994

Lima.

CHANAMÉ ORBE, Raúl

1995

Constitución didáctica. Ed. San Marcos. Lima.

DELGADO PORRES, Antonio

1998

Panorámica de la protección civil y penal en materia de propiedad intelectual. Civitas. Madrid. 
DECRETOLEGISLATTVO $N^{\circ} 822$

1996 Lima.

KLASSE, Isay

1986

Lecturas profesionales. ¿Cómo nace un libro? Bowker Editores Argentinos. Buenos Aires.

LIPSZYC, Delia

1993

Derecho de Autory Derechos Conexos. UNESCO, CERLALC, Zavalía. Buenos Aires.

ORGANIZACIÓNMUNDIAL DELA PROPIEDADINTELECTUAL (OMPI)

1978

Guía del Convenio de Berna. Ginebra.

1980

Glosario de derecho de autor y derechos conexos. Ginebra.

PIZARRO DÁVILA, Edmundo

1985

El Derecho de Autor Lima.

RUIZ-CASTILLOBASALA, José

1987

Memorias de un editor: el apasionante mundo del libro. Fundación Germán Sánchez Ruipérez: Pirámide. Madrid.

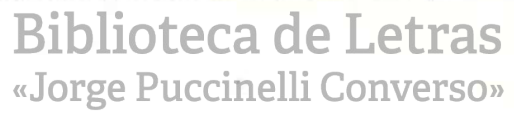

